\title{
The USTC co-opts an ancient machinery to drive piRNA transcription in C. elegans
}

\author{
Chenchun Weng, ${ }^{1,6}$ Joanna Kosalka, ${ }^{2,6}$ Ahmet C. Berkyurek, ${ }^{2,6}$ Przemyslaw Stempor, ${ }^{2}$ Xuezhu Feng, ${ }^{1}$ \\ Hui Mao, ${ }^{1}$ Chenming Zeng, ${ }_{1}^{1}$ Wen-Jun Li, ${ }^{3}$ Yong-Hong Yan, ${ }^{3}$ Meng-Qiu Dong, ${ }^{3}$ Natalia Rosalía Morero, ${ }^{4}$ \\ Cecilia Zuliani, ${ }^{4}$ Orsolya Barabas, ${ }^{4}$ Julie Ahringer, ${ }^{2}$ Shouhong Guang, ${ }^{1}$ and Eric A. Miska ${ }^{2,5}$ \\ ${ }^{1}$ Hefei National Laboratory for Physical Sciences at the Microscale, School of Life Sciences, University of Science and Technology \\ of China, Hefei, Anhui 230027, China; ${ }^{2}$ Wellcome Cancer Research UK Gurdon Institute, University of Cambridge, Cambridge \\ CB2 1QN, United Kingdom; Department of Genetics, University of Cambridge, Cambridge CB2 3EH, United Kingdom; ${ }^{3}$ National \\ Institute of Biological Sciences, Beijing 102206, China; ${ }^{4}$ Structural and Computational Biology Unit, European Molecular Biology \\ Laboratory (EMBL), 69117 Heidelberg, Germany; ${ }^{5}$ Wellcome Sanger Institute, Cambridge CB10 1SA, United Kingdom
}

Piwi-interacting RNAs (piRNAs) engage Piwi proteins to suppress transposons and nonself nucleic acids and maintain genome integrity and are essential for fertility in a variety of organisms. In Caenorhabditis elegans, most piRNA precursors are transcribed from two genomic clusters that contain thousands of individual piRNA transcription units. While a few genes have been shown to be required for piRNA biogenesis, the mechanism of piRNA transcription remains elusive. Here we used functional proteomics approaches to identify an upstream sequence transcription complex (USTC) that is essential for piRNA biogenesis. The USTC contains piRNA silencing-defective 1 (PRDE-1), SNPC-4, twenty-one-U fouled-up 4 (TOFU-4), and TOFU-5. The USTC forms unique piRNA foci in germline nuclei and coats the piRNA cluster genomic loci. USTC factors associate with the Ruby motif just upstream of type I piRNA genes. USTC factors are also mutually dependent for binding to the piRNA clusters and forming the piRNA foci. Interestingly, USTC components bind differentially to piRNAs in the clusters and other noncoding RNA genes. These results reveal the USTC as a striking example of the repurposing of a general transcription factor complex to aid in genome defense against transposons.

[Keywords: piRNA; PRDE-1; Ruby motif; SNPC; SNPC-4; snRNA; TOFU-4; TOFU-5; U6 RNA]

Supplemental material is available for this article.

Received July 28, 2018; revised version accepted October 19, 2018.

Piwi-interacting RNAs (piRNAs) are a class of small (21- to 30-nucleotide [nt]) RNAs that associate with Piwi proteins, a highly conserved subclass of Argonaute proteins, and play significant roles in fertility and genome stability (Lin and Spradling 1997; Cox et al. 1998; Girard et al. 2006; Carmell et al. 2007; Houwing et al. 2007; Batista et al. 2008; Das et al. 2008; Palakodeti et al. 2008). piRNAs program genome elimination during the sexual reproduction in ciliates (Chalker and Yao 2011) and engage in sex determination, virus defense, regeneration, and neoblast function in animals (Reddien et al. 2005; Palakodeti et al. 2008; Schnettler et al. 2013; Zhao et al. 2013; Kiuchi et al. 2014). piRNAs also play important roles in male fertility in humans (Gou et al. 2017). In Caenorhabditis elegans, piRNAs preserve genome integrity in the germline by recognizing and silencing "nonself" genomic loci such as transposons or other foreign nucleic acids and

\footnotetext{
${ }^{6}$ These authors contributed equally to this work. Corresponding authors: eam29@cam.ac.uk, sguang@ustc.edu.cn Article published online ahead of print. Article and publication date are online at http://www.genesdev.org/cgi/doi/10.1101/gad.319293.118. Freely available online through the Genes \& Development Open Access option.
}

induce chromatin modifications (Malone and Hannon 2009; Ashe et al. 2012; Bagijn et al. 2012; Feng and Guang 2013; Luteijn and Ketting 2013; Mao et al. 2015). In addition to the function of piRNAs in the germline, a recent report provided evidence for the presence of piRNA factors such as PRDE-1 (piRNA silencing-defective 1) and PRG-1 in C. elegans neuronal cells (Kim et al. 2018).

C. elegans piRNAs are also referred to as $21 \mathrm{U}-\mathrm{RNAs}$, given that they are predominantly $21 \mathrm{nt}$ in length and have a strong bias toward 5' monophosphorylated uracil (Batista et al. 2008; Das et al. 2008; Bagijn et al. 2012; $\mathrm{Gu}$ et al. 2012). piRNAs silence transposons and proteincoding genes independently of the endonuclease or slicing activities of the Piwi protein PRG-1. Instead, piRNAs scan for foreign sequences while allowing mismatched pairing with the targeted mRNAs (Ashe et al. 2012; Bagijn et al. 2012; Shirayama et al. 2012). Upon targeting, the piRNA/PRG-1 complex recruits RNA-dependent RNA polymerase $(\mathrm{RdRP})$ to elicit the generation of secondary

(C) 2019 Weng et al. This article, published in Genes \& Development, is available under a Creative Commons License (Attribution 4.0 International), as described at http://creativecommons.org/licenses/by/4.0/. 
siRNAs, referred to as "22G-RNAs." The 22G-RNAs are then loaded onto worm-specific Argonaute proteins (WAGOs) to conduct gene silencing processes (Ashe et al. 2012; Bagijn et al. 2012; Lee et al. 2012; Shirayama et al. 2012; Mao et al. 2015). Meanwhile, "self" mRNAs are protected from piRNA-induced silencing by the CSR-1 Argonaute pathway (Shirayama et al. 2012; Conine et al. 2013; Seth et al. 2013). Therefore, piRNAs are required to initiate the epigenetic silencing, yet the inheritance of the silencing requires 22G-RNAs (Ruby et al. 2006; Batista et al. 2008; Das et al. 2008; Bagijn et al. 2012; Gu et al. 2012; Feng and Guang 2013).

Unlike siRNAs and microRNAs (miRNAs), the biogenesis of piRNAs is a Dicer-independent process (Klattenhoff and Theurkauf 2008; Siomi et al. 2011; Grishok 2013). In Drosophila, the long piRNA precursors are transcribed from two different genomic sources, the unistrand and dual-strand clusters, which are further processed and amplified by distinct factors to conduct their respective functions (Brennecke et al. 2007; Saito et al. 2007; Klattenhoff et al. 2009; Handler et al. 2011; Pane et al. 2011; Ipsaro et al. 2012; Goriaux et al. 2014; Mohn et al. 2014; Vourekas et al. 2015; Czech and Hannon 2016). The mouse piRNAs are classified into prepachytene and pachytene piRNAs based on their expression patterns (Aravin et al. 2008; Li et al. 2013)_pachytene piRNA transcription distinctively requiring the transcription factor A-MYB (Li et al. 2013).

piRNAs are expressed in the germline from thousands of genomic loci and mostly from two large genome clusters on chromosome IV. They are first transcribed by RNA polymerase II (Pol II) that initiates precisely $2 \mathrm{nt}$ upstream of the $5^{\prime}$ end of mature piRNAs to generate 25- to 29-nt capped small RNA (csRNA) precursors (Cecere et al. 2012; Gu et al. 2012; Weick et al. 2014). Next, the precursors are decapped at the $5^{\prime}$ end, the first $2 \mathrm{nt}$ are removed, and the extra nucleotides at $3^{\prime}$ ends are trimmed off and methylated to produce mature piRNAs (Billi et al. 2012; Montgomery et al. 2012; de Albuquerque et al. 2014; Weick et al. 2014; Tang et al. 2016). C. elegans encodes two Piwi proteins: PRG-1 and PRG-2. Whereas the function of PRG-2 is unknown, mature piRNAs associate with PRG-1 to conduct their functions (Batista et al. 2008; Das et al. 2008; Bagijn et al. 2012). The binding of piRNAs to PRG-1 is important for their production and silencing effect of piRNAs. piRNAs are absent in prg-1 mutant animals (Wang and Reinke 2008; Gu et al. 2012), and loss of piRNA/PRG-1 complexes leads to reduced fertility (Batista et al. 2008; Das et al. 2008; Wang and Reinke 2008). Interestingly, untrimmed piRNAs with $3^{\prime}$ extensions are stable and associate with PRG-1 yet are unable to robustly recruit other downstream factors and therefore compromise the silencing effect (Tang et al. 2016).

Two types of piRNAs have been described in C. elegans. Type I piRNAs are predominantly transcribed from two broad regions on chromosome IV and contain an 8-nt upstream Ruby motif (CTGTTTCA) and a small YRNT motif in which the $T$ corresponds to the first $U$ of the piRNA. Type II piRNAs are present outside of chromosome IV and lack the Ruby motif (Ruby et al. 2006; Gu et al. 2012). Each
piRNA is independently transcribed as a short RNA precursor by RNA Pol II. Recent work identified PRDE-1 and SNPC-4 in a complex that binds to the Ruby motif of type I piRNA loci, which are essential for the transcription of piRNA precursors (Kasper et al. 2014; Weick et al. 2014). A Forkhead family transcription factor, unc-130, was shown to bind piRNA promoters and has been implicated in piRNA transcription (Cecere et al. 2012). PID-1 may function to promote piRNA processing in the cytoplasm (de Albuquerque et al. 2014). A genome-wide RNAi screen identified seven twenty-one-U fouled-ups (TOFUs) that are engaged in distinct expression and processing steps of piRNAs (Goh et al. 2014). However, it is still unclear how the transcription of piRNA precursors is controlled. Here, we used functional proteomics and identified the upstream sequence transcription complex (USTC) containing PRDE-1, SNPC-4, TOFU-4, and TOFU-5, which bound to the promoters of piRNA precursors to drive their expression in the C. elegans germline.

\section{Results}

Proteomic screens identify a complex containing PRDE-1, SNPC-4, TOFU-4, and TOFU-5 proteins

Our previous study identified prde-1 as being essential for piRNA generation in C. elegans (Weick et al. 2014). Later, it was found that a small nuclear RNA (snRNA)activating complex protein, SNPC-4, colocalize with PRDE-1 and promotes piRNA biogenesis (Kasper et al. 2014). To further understand the transcriptional regulation of piRNAs, we searched for proteins that interact with PRDE-1 using coimmunoprecipitation mass spectrometry (co-IP-MS). Surprisingly, SNPC-4, TOFU-4, and TOFU-5, which were identified in a previous RNAi screen (Goh et al. 2014), were among the top candidates (Fig. 1A, B; Supplemental Fig. S1A; Supplemental Table S1). These proteins significantly separate together from the PRDE-1 knockout immunoprecipitation (Fig. 1B). Thus, we aimed to further investigate whether PRDE-1, SNPC-4, TOFU-4, and TOFU-5 function as a complex in piRNA biogenesis. The physical evidence for the complex was further supported by size exclusion chromatography of C. elegans nuclear extracts followed by Western blot analysis. This showed that PRDE-1 and TOFU-5 were present in fractions ranging between 200 and $354 \mathrm{kDa}$. This is consistent with the expected size of the USTC (251 kDa), assuming 1:1:1:1 stoichiometry (Fig. 1C). To identify proteins directly binding to PRDE-1, we performed yeast two-hybrid $(\mathrm{Y} 2 \mathrm{H})$ experiments and found TOFU-4. This interaction was confirmed by reciprocal $\mathrm{Y} 2 \mathrm{H}$ experiments. Considering the previously observed localization dependence between PRDE-1 and SNPC-4 (Kasper et al. 2014), we wanted to search for proteins interacting with SNPC4. Interestingly, SNPC-4 was found to interact directly with TOFU-5 in $\mathrm{Y} 2 \mathrm{H}$ experiments. This interaction was confirmed by co-IP-MS of TOFU-5 (in animals expressing TOFU-5::GFP) and Y2H experiments using TOFU-5::GFP as a bait (Supplemental Fig. S1B; Supplemental Table S1). Altogether, these results raise strong evidence that PRDE- 


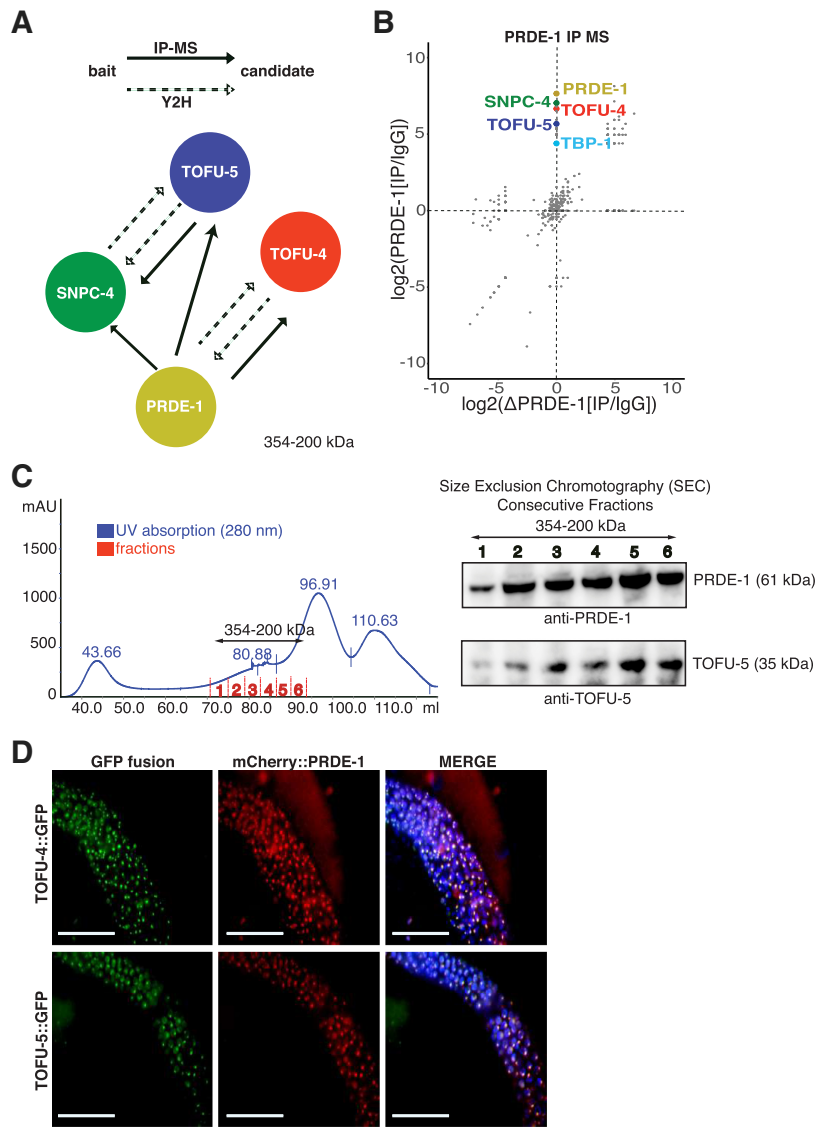

Figure 1. Functional proteomics identify the USTC. (A) Summary of protein-protein interaction experiments between PRDE-1, SNPC-4, TOFU-4, and TOFU-5. (B) Scatter plot showing the comparison of $\log _{2}$ values normalized to IgG of all found proteins in PRDE-1 wild type and prde-1(mj207) co-IP-MS. USTC components and TATA-box-binding protein 1 (TBP-1) are displayed. (C) Size exclusion chromatography of nuclear extracts followed by Western blot for USTC components PRDE- 1 and TOFU5. Fractions with the highest concentrations of PRDE-1 and TOFU-5 are shown. (D) Subcellular colocalization of TOFU-4:: GFP and TOFU-5::GFP (green) with mCherry:PRDE-1 (red) in young adult germline nuclei. Bar, $20 \mu \mathrm{m}$.

1, SNPC-4, TOFU-4, and TOFU-5 function as a complex during piRNA transcription.

To understand these protein-protein interactions in detail, we generated single-copy GFP-3xFlag-tagged TOFU-4 and TOFU-5 (TOFU-4::GFP and TOFU-5::GFP, respectively) transgenic strains using the Mos1-mediated single-copy insertion (MosSCI) technology (Frokjaer-Jensen et al. 2008). The TOFU-4::GFP and TOFU-5::GFP transgenes rescued the tofu- 4 and tofu- 5 mutant phenotypes, respectively, advocating that the tagged proteins could recapitulate the functions of endogenous proteins (Supplemental Fig. S1C,D). Both TOFU-4::GFP and TOFU-5:: GFP exhibit distinct foci in the germline nuclei (Supplemental Fig. S2A,B). Previous work showed that PRDE-1 colocalizes with SNPC-4 and forms distinct foci in germline cell nuclei (Kasper et al. 2014; Weick et al. 2014).
We immunostained PRDE-1 with anti-PRDE-1 antibody in TOFU-5::GFP animals and found that PRDE-1 and TOFU-5 also colocalize with each other in the germline nuclei (Supplemental Figs. S1E, S2C). To validate that PRDE-1, TOFU-4, and TOFU-5 function as a complex, we crossed the mCherry::PRDE-1 transgene into TOFU4::GFP- and TOFU-5::GFP-expressing animals (Fig. 1D). Consistently, both TOFU-4 and TOFU-5 are colocalized with PRDE-1 as distinct foci in germ cell nuclei. Importantly, nuclei in the mitotic zone exhibited two foci, and nuclei in the meiotic zone exhibited one focus, consistent with the ploidy of the cells (Supplemental Fig. S1E; Kasper et al. 2014). Therefore, we conclude that PRDE-1, SNPC-4, TOFU-4, and TOFU-5 likely function as a protein complex to engage in piRNA biogenesis.

\section{PRDE-1, SNPC-4, TOFU-4, and TOFU-5 are enriched at piRNA clusters and coat the Ruby motif}

SNPC-4 has been shown previously to associate with the chromosome IV piRNA clusters, and the binding depends on the presence of PRDE-1 (Kasper et al. 2014). To test whether PRDE-1, TOFU-4, and TOFU-5 colocalize with SNPC-4 at piRNA clusters, we performed ChIP-seq (chromatin immunoprecipitation [ChIP] combined with high-throughput sequencing) experiments with all four factors in young adults, when piRNA expression is at its peak (Batista et al. 2008; Das et al. 2008); all experiments were done in duplicates and normalized to merged input libraries (Supplemental Fig. S3). We found that all four factors have similar genome-wide binding profiles, with strong enrichment on chromosome IV piRNA clusters (Fig. 2A,B; Supplemental Fig. S4A,B), although SNPC-4 did not appear enriched on the smaller piRNA cluster (cluster I). However, this might be a reflection of lower signal to noise ratio of the SNPC-4 ChIP-seq experiments (Fig. 2A). Finally, PRDE-1, SNPC-4, TOFU-4, and TOFU-5 all "coated" piRNA genes broadly, showing signal around piRNA genes above the genome average and a peak upstream of the transcription start site (TSS) (Fig. 2C).

C. elegans piRNAs are categorized into type I and type II piRNAs. Type I piRNAs feature the Ruby motif upstream of the TSS of each piRNA transcription unit and are found mostly in the two chromosome IV piRNA clusters, whereas type II piRNAs are more distributed and lack the Ruby motif (Ruby et al. 2006; Gu et al. 2012). To examine whether PRDE-1, SNPC-4, TOFU-4, and TOFU-5 exhibit a preference toward a class of piRNA genes, we plotted heat map profiles of the USTC components around type I and type II piRNA TSSs, respectively (Fig. 3A; Supplemental Fig. S5A). Consistent with our previous finding that PRDE-1 is not required for type II piRNA transcription (Weick et al. 2014), little enrichment was found at these sites (Supplemental Fig. S5A). However, SNPC-4 and TOFU-5 were enriched at type II piRNA genes (Supplemental Fig. S5A). We observed that all four factors exhibit robust enrichment around type I piRNA genes (Fig. 3A) and that $\mathrm{Z}$ scores overlapped the Ruby motif (Fig. 3B). Combining the proteomic experiments, subcellular colocalization, 


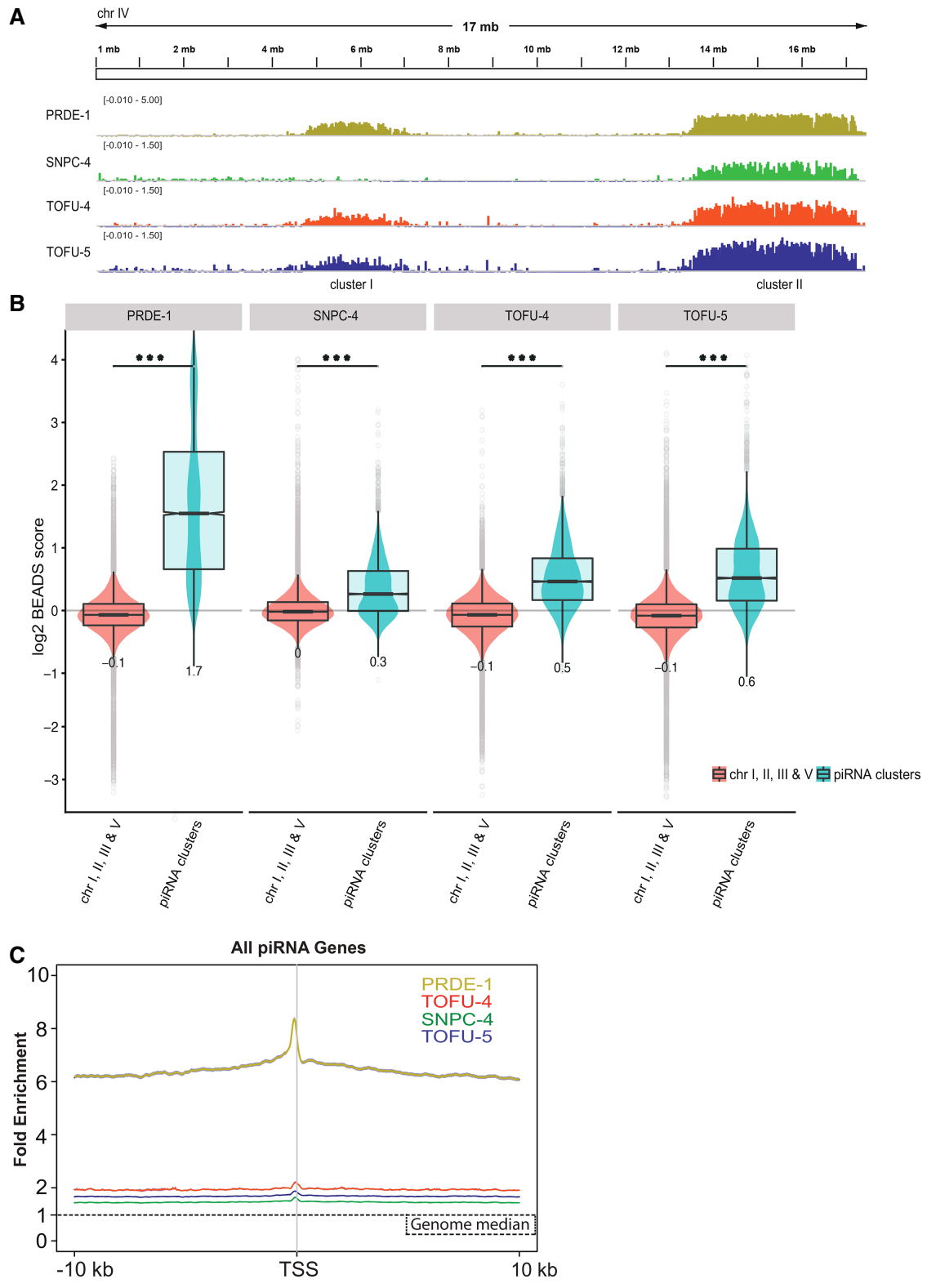

Figure 2. USTC factors coat the piRNA clusters on chromosome IV. (A) The binding profiles of USTC factors across chromosome IV. ChIP signal was normalized with rBEADS (bias elimination algorithm for deep sequencing) and $\log _{2}$ transformed (PRDE-1 was scaled differently). (B) Quantification of ChIP-seq signal on chromosome IV piRNA clusters and other somatic chromosomes (I, II, III, and V). The signal was calculated in $1-k b$ bins. All USTC factors are significantly enriched on piRNA clusters. $(C)$ Enrichment profile of USTC factors around the TSSs of all piRNA genes. The plot is anchored on the first U nucleotide of each piRNA. and enrichment at type I piRNA genes, we conclude that PRDE-1, SNPC-4, TOFU-4, and TOFU-5 function as a protein complex to promote the biogenesis of piRNAs by binding to the upstream sequence of piRNA genes. We therefore named this complex the USTC.

The binding of TOFU-5 to the piRNA clusters depends on the other USTC components

A previous study found that the concentration of SNPC-4 at piRNA loci depends on PRDE-1 (Kasper et al. 2014). To investigate the genetic requirements of distinct USTC components for the binding of the piRNA loci, we first examined whether the localization of TOFU-5 to the piRNA loci depends on the presence of other USTC factors.

We crossed the TOFU-5::GFP strain to tofu-4(tm6157) and prde-1(mj207) mutants and found that TOFU-5 failed to form the subnuclear foci in germline cells in young adult animals (Fig. 4A). Additionally, ChIP-qPCR (ChIP combined with quantitative PCR) of TOFU-5 indicated that TOFU-5 does not bind to piRNA clusters in the absence of PRDE-1 or TOFU-4 (Fig. 4B). SNPC-4 is an essential gene required for the development of C. elegans. snpc4 mutant animals are embryonic- or larval-lethal (Kasper et al. 2014). We therefore crossed TOFU-5::GFP animals with snpc-4(tm4568/hT2) balanced mutant animals and found that TOFU-5 fails to form the subnuclear foci in snpc-4(tm4568) homozygous mutant young adult offspring of these animals (Fig. 4C). Remarkably, in snpc-4 (tm4568) mutants, TOFU-5::GFP accumulates in the germline syncytium, further confirmed by knocking down snpc-4 by feeding RNAi (Fig. 4C). Both SNPC-4 and TOFU-5 contain a conserved SANT (Swi3 [switching-defective protein 3], Ada2 [adaptor 2], N-CoR [nuclear 
A

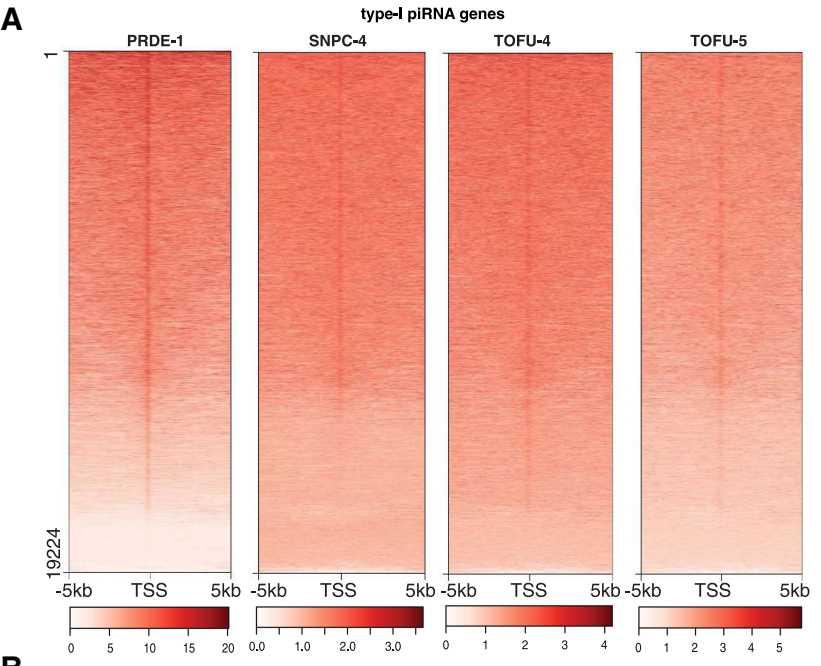

B

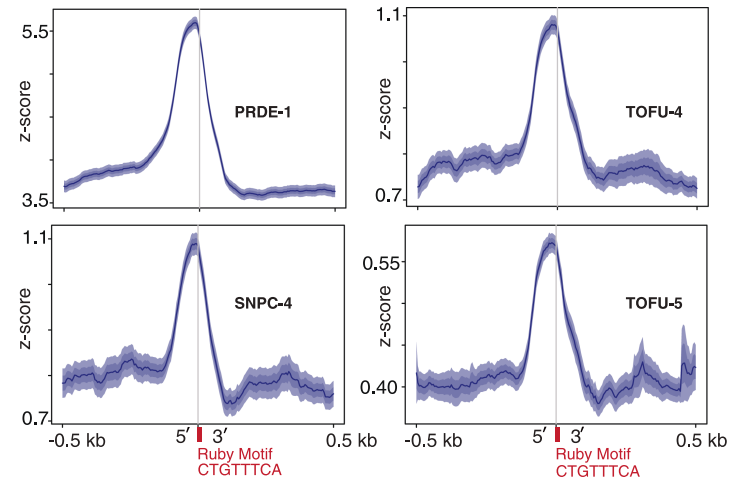

Figure 3. USTC factors are enriched at the Ruby motif upstream of type I piRNA genes. (A) Heat map of ChIP-seq binding profiles of USTC factors around type I piRNA TSSs. The BEADS normalization score is plotted $5 \mathrm{~kb}$ upstream of and downstream from the first U base of piRNAs. (B) Enrichment profile of USTC factors around the Ruby motif upstream of type I piRNA genes within a 500-base-pair (bp) window.

receptor corepressor], and TFIIIB [transcription factor IIIB]) domain, which may bind to DNA sequences (Boyer et al. 2004). We constructed a TOFU-5(*SANT)::GFP transgenic animal by deleting the SANT domain (Supplemental Fig. S5B). Unlike wild-type TOFU-5, the TOFU-5 $\left({ }^{*}\right.$ SANT):: GFP fails to form the piRNA foci and is instead enriched in the germline syncytium (Fig. 4D). Consistently, TOFU-5(*SANT)::GFP fails to bind to piRNA clusters, as shown by ChIP assay followed by real-time PCR (Fig. 4E). The similar cytoplasmic locations of TOFU-5 (*SANT)::GFP and wild-type TOFU-5 in the absence of SNPC-4 suggest that the SANT domain of TOFU-5 might be required for interaction between SNPC-4 and TOFU-5. In addition, $\mathrm{Y} 2 \mathrm{H}$ experiments indicated that the interaction between SNPC-4 and TOFU-5 required the amino acid residues between 768 and 858 of SNPC-4, in which the SANT domain is located. Together, we concluded that the ability of TOFU-5 to bind piRNA clusters and form the piRNA foci depends on other components of the USTC.
The binding of TOFU-4 to piRNA clusters depends on other USTC factors

Next, we examined whether the binding of TOFU-4 to the piRNA loci depends on the presence of other USTC components. We crossed the TOFU-4::GFP transgene into prde-1(mj207) mutants and found that PRDE-1 was required for the formation of TOFU-4 piRNA foci (Fig. $5 \mathrm{~A})$ and the binding to piRNA clusters (Fig. 5B). We introduced TOFU-4::GFP into snpc-4(tm4568/hT2) and tofu-5 (tm6408/hT2) and found that TOFU-4 fails to form piRNA foci in snpc-4(tm4586) and tofu-5(tm6408) homozygous mutants, which was further confirmed by knocking down snpc-4 by feeding RNAi (Fig. 5C). Therefore, we conclude that, similar to our observation for TOFU-5codependent localization, the binding of TOFU-4 to piRNA clusters depends on the presence of other USTC factors.

\section{The USTC binds to additional sets of noncoding genes}

In addition to the piRNA clusters, SNPC-4 binds canonical SNAPc targets, including RNA Pol II and RNA Pol III transcribed noncoding RNA (ncRNA) genes (Kasper et al. 2014). We therefore investigated whether PRDE-1, SNPC-4, TOFU-4, and TOFU-5 also bound together to other regions in the genome by examining peaks for each factor outside of the piRNA clusters. We found little evidence for PRDE-1 binding outside the piRNA clusters (Fig. 6). However, both SNPC-4 and TOFU-5 were found to bind to a number of snRNA and small nucleolar RNA (snoRNA) genes. As for TOFU-4, we did not observe many peaks, but this might be a reflection of the signal to noise ratio of the TOFU-4 ChIP-seq experiment. Interestingly, SNPC-4 and TOFU-5 are also enriched on specific classes of transposable elements (Supplemental Fig. S6). These results suggest that, in addition to their ancestral functions, including ncRNA transcription, USTC components might have acquired other functions, such as promoting piRNA biogenesis (Fig. 7).

Identification of TOFU-3 and TATA-box-binding protein 1 (TBP-1) as additional factors required for TOFU-5 binding to piRNA clusters

To further understand the function of the USTC in promoting piRNA transcription, we searched for factors that are required for the formation of TOFU- 5 subnuclear piRNA foci. We selected a number of candidate genes from our proteomic experiments and previous genomewide RNAi screens and carried out a focused candidate RNAi screen for TOFU-5 foci (Supplemental Table S2; Cecere et al. 2012; Goh et al. 2014). Interestingly, we found that both TOFU-3, a candidate from the genomewide RNAi screen, and TBP-1, a protein that we identified through proteomics, are required for the formation of TOFU-5 piRNA foci (Supplemental Fig. S7A,B; Supplemental Table S2). However, we did not identify any forkhead transcription factors in this screen, which had been 
A

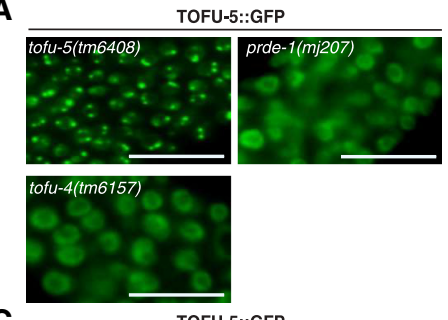

C

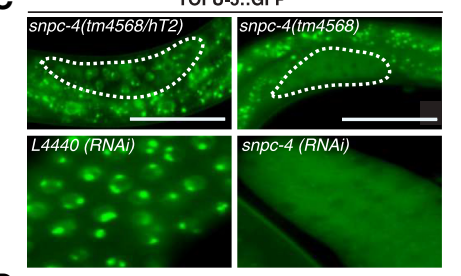

D

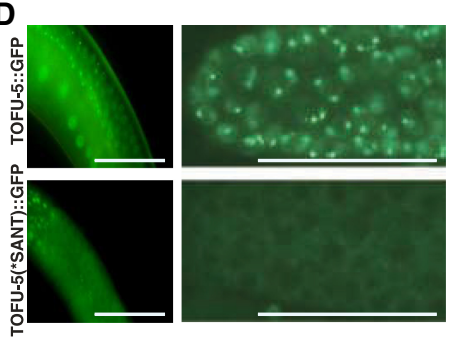

B

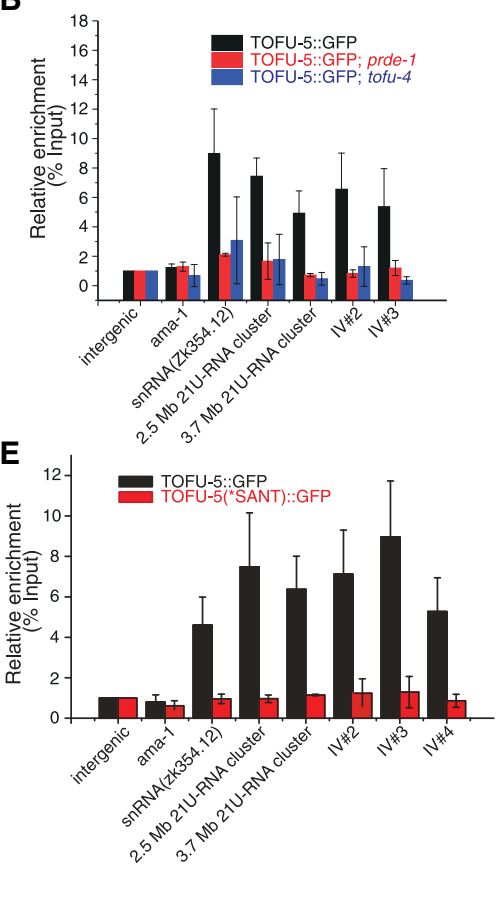

Figure 4. Genetic requirements of TOFU-5 binding to piRNA clusters. $(A)$ Images of germline nuclei of young adult animals expressing TOFU-5::GFP. Bar, $20 \mu \mathrm{m}$. (B) Relative enrichment of TOFU-5 by ChIP assay with an anti-GFP antibody in the indicated young adult animals. $n=3 \pm$ SD. Images of germline nuclei of the indicated animals. Primer sets are listed in Supplemental Table S4. (C) TOFU-5::GFP failed to localize to nuclei in snpc-4(-) young adult animals or upon RNAi feeding against SNPC-4. Bar, $20 \mu \mathrm{m}$. $(D)$ Images of the indicated germline nuclei of young adult animals. TOFU-5 $\left({ }^{*}\right.$ SANT $)::$ GFP failed to localize to nuclei in the distal germline. Bar, $20 \mu \mathrm{m}$. (E) Relative enrichment of TOFU-5::GFP and TOFU-5(*SANT)::GFP by ChIP assay with an anti-GFP antibody in young adult animals. $n=3 \pm$ SD. shown previously to recognize the Ruby motif (Supplemental Table S2).

\section{Discussion}

Here, by a series of proteomics, imaging, and ChIP-seq experiments, we demonstrate that the four proteins PRDE-1, SNPC-4, TOFU-4, and TOFU-5 function as a complex and bind to the promoter sequences of individual piRNA transcription units. This complex localizes to subnuclear foci and exhibits concentrated binding across the two piRNArich domains on chromosome IV. We found that the two categories of piRNAs, classified by the presence of the Ruby motif in their promoter region, may use different combinations of the USTC factors for the promoter recognition. While all of the USTC factors bind to the promoters of piRNA genes, SNPC-4 and TOFU-5 are also enriched on other classes of ncRNA (Figs. 6,7).

\section{Using functional proteomic methods to identify the USTC}

Previously, forward genetic screens have identified PRDE-1 and PID-1 as required factors for piRNA biogenesis in C. elegans (de Albuquerque et al. 2014; Weick et al. 2014). Using biochemical approaches, a Forkhead family transcription factor, unc-130, was shown to bind piRNA promoters (Cecere et al. 2012). Additionally, a genomewide RNAi screening identified TOFU genes that are engaged in expression and distinct processing steps of piRNAs (Goh et al. 2014). Here, we combined a series of functional proteomic methods and characterized a USTC that contains PRDE-1, SNPC-4, TOFU-4, and TOFU-5.
To our knowledge, this is the first complex involved in piRNA biogenesis in C. elegans that has been found. These proteins can interact with each other in a codependent manner and bind to the upstream promoter region of the piRNA transcription units. We further used genomewide analyses and cell biology approaches and demonstrated a mutual dependency of the components of the USTC in their ability to form the piRNA foci in the germline. Strikingly, one of the USTC factors, SNPC-4, was reported previously as a part of an ancient complex for ncRNA transcription with RNA Pol II and Pol III (Kasper et al. 2014). In summary, we discovered a unique complex that differentially enriches over type I and type II piRNA genes and might engage the transcriptional machinery.

Interestingly, UNC-130, a member of the forkhead transcription factor family, has been reported previously to bind piRNA gene promoters in vitro (Cecere et al. 2012). However, we did not observe UNC-130 or any other forkhead transcription factors' enrichment with our mass spectrometry approaches using physiological conditions. This might suggest alternative mechanisms that are potentially involved in piRNA biogenesis. It will be interesting to understand the detailed role of forkhead transcription factors using biochemical and proteomic approaches in the future.

\section{The recognition of piRNA transcription units}

C. elegans piRNAs are classified into two types. Type I piRNAs are predominantly transcribed from two broad regions from chromosome IV, with an 8-nt upstream Ruby motif (CTGTTTCA) and a small YRNT motif. Type II piRNAs lack the Ruby motif and are present outside of 


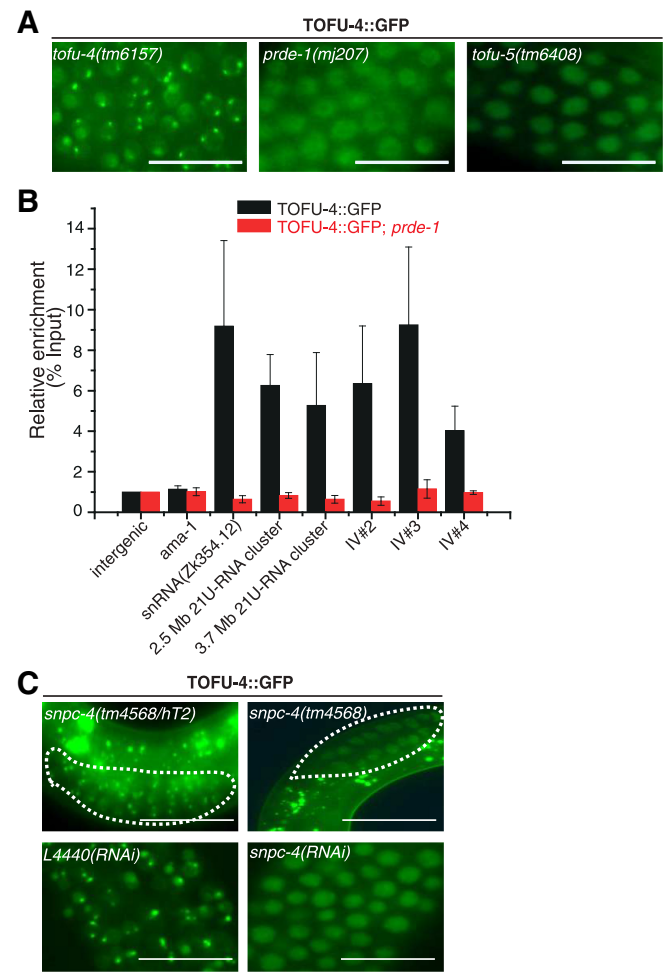

Figure 5. Genetic requirement of TOFU-4 binding to piRNA clusters. $(A)$ Images of the indicated germline nuclei of young adult animals expressing TOFU-4::GFP. Bar, $20 \mu \mathrm{m}$. (B) Relative enrichment of TOFU- 4 by ChIP assay with an anti-GFP antibody. $n=3 \pm$ SD. Primer sets are listed in Supplemental Table S4. (C) TOFU-4:: GFP fails to form nuclear foci in the germline in $s n p c-4(-)$ young adult animals or upon RNAi feeding against SNPC-4.

chromosome IV (Ruby et al. 2006; Gu et al. 2012). It has been shown previously that PRDE-1 is required for type I piRNA biogenesis (Weick et al. 2014). The forkhead transcription factors were reported to recognize the Ruby motif as well (Cecere et al. 2012). Here, we showed that, while the four factors of USTC bind type I piRNA promoters, PRDE-1 and TOFU-4 exhibit less binding activity to type II piRNA promoters. Additionally, SNPC-4 and TOFU-5 exhibit binding activity toward type II piRNA promoters. Whether this distinct pattern reflects Ruby-like sequences in type II piRNA promoters that exhibit weaker binding affinity or whether other protein factors are involved in the promoter recognition requires further investigation.

Remarkably, while SNPC-4 and TOFU-5 bind to overlapping sets of non-piRNA promoters, PRDE-1 lacks such binding sites. Therefore, the USTC may play a central role in defining piRNA transcription units and separate piRNA precursors from pre-mRNAs for downstream processing and maturation. RNA Pol II transcribes proteincoding mRNA and also a variety of shorter ncRNAsmost notably spliceosomal U1 and U2 snRNAs (LykkeAndersen and Jensen 2007; Egloff et al. 2008). Although both piRNA precursors and pre-mRNAs are transcribed by RNA Pol II, the USTC may direct distinct transcription and processing machineries to piRNA units. It will be very interesting to examine the coupling between transcriptional regulation and processing and $3^{\prime}$ end trimming in the biogenesis of piRNAs. Experiments investigating the binding pattern of each component in the absence of other USTC factors will further enlighten our understanding of their mutual regulatory relationships.

\section{TBP-1 and piRNA biogenesis}

tbp-1 encodes the C. elegans ortholog of the human TBP, which plays important roles in transcriptional regulation. TBP-1 has been shown to provide TFIID-like basal transcription activity in human and C. elegans extracts, bind specifically to a TATA-box sequence, and interact with TFIIA and TFIIB transcription factors. $t b p-1$ activity is required for embryonic and larval development as well as for normal rates of post-embryonic growth. In Drosophila, Moonshiner also drives the transcription of piRNA clusters by recruiting TBP-related factor TRF-2 (Andersen et al. 2017).

The function of $t b p-1$ in piRNA biogenesis is not yet known. Here, we showed that although TBP-1 did not accumulate in the piRNA foci, it was required for the formation of the piRNA foci and was found to interact with PRDE-1 (Fig. 1B; Supplemental Fig. S7A,B). We speculate that $t b p-1$ and the Ruby motif may be required together

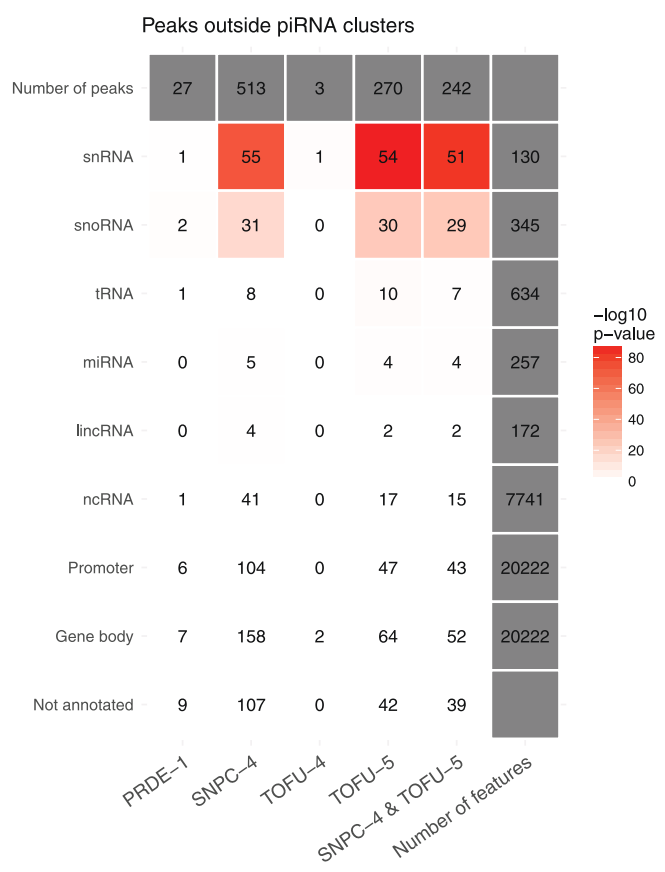

Figure 6. Binding sites of USTC factors outside the piRNA clusters. Gene types of USTC factor-binding sites were analyzed with selected annotations from Ensemb1 92. The heat map shows highconfidence USTC factor-binding sites overlapping with selected annotations from Ensembl 92. The bindings sites were detected using overlaps between peak calls on individual replicates. The numbers denote direct overlaps between the peaks and annotated genomic loci, and colors identify the estimation of overlap significance $\left(-\log _{10}\right.$ transformed $P$-value of hypergeometric test for overrepresentation). 


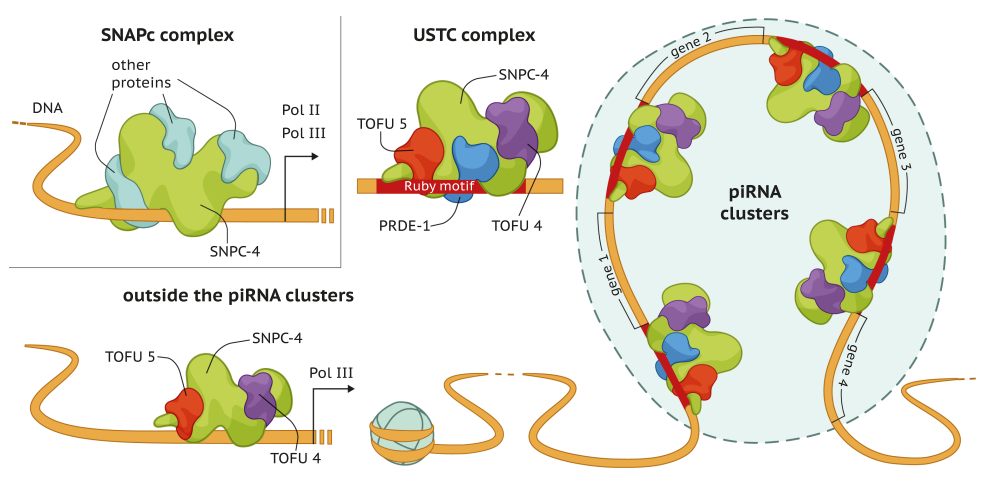

Figure 7. A model for the role of the USTC inside and outside piRNA clusters. Proposed model for the mechanism of the USTC. SNPC-4, TOFU-4, and TOFU-5 bind to ncRNAs outside the piRNA clusters. Together with PRDE-1, all four factors of the USTC engage in piRNA biogenesis. for USTC binding to piRNA promoters. Here, TBP-1 may act as a bridge to bend the DNA so that the USTC comes closer to the piRNA promoter sequences. Further investigation of the roles of TBP-1 in piRNA biogenesis will shed light on the specific mechanistic understanding of the transcription regulation of piRNAs.

\section{Chromosome modification in piRNA transcription}

Both SNPC-4 and TOFU-5 contain SANT domains (Boyer et al. 2004). Sequence analysis of the SANT domain indicates a strong similarity to the DNA-binding domain (DBD) of Myb-related proteins. SANT domains have been shown to couple histone tail binding to enzymatic activity, including histone acetylation and deacetylation and ATP-dependent chromatin remodeling. Small deletions in the SANT domains may lead to a complete loss of function of the proteins. Here, we show that the deletion of the SANT domain of TOFU-5 relocalizes TOFU5 from the nucleus to the cytoplasm, disables its ability to bind to piRNA promoters, and alters the piRNA foci. The SANT domain-containing proteins can influence chromatin state, suggesting that SNPC-4 and TOFU-5 can modulate nucleosome organization and/or histone modifications in the piRNA regions. Consistently, the piRNA regions exhibited decreased nucleosome density in young adult animals (Cecere et al. 2012). It is still unclear whether the presence of the SANT domain is required for the cytoplasm-to-nucleus import of TOFU-5.

Chromatin modifications play important roles in small RNA biogenesis. In Drosophila, transcription of piRNA clusters is enforced through RNA Pol II preinitiation complex formation within repressive heterochromatin, in which the heterochromatin protein-1 variant Rhino recruits Moonshiner (Andersen et al. 2017). In C. elegans, two piRNA clusters on chromosome IV are nucleosomedepleted regions (Cecere et al. 2012). In our PRDE-1 Y2H experiment, set-6 (a gene encoding a putative $\mathrm{H} 3 \mathrm{~K} 9$ methyltransferase) and set-16 (a gene encoding a putative H3K4 methyltransferase) were identified. However, these two proteins and other chromatin modification factors were not required for the formation of piRNA foci (Supplemental Table S1). Therefore, we speculate that either the biogenesis of piRNAs is independent of chromatin modifi- cation processes or certain chromatin factors act together to promote the formation of piRNA foci. Further analysis of the properties of chromatin, including histone modifications, in the germline will be necessary to directly explore the relationship between the chromatin state, the USTC, and piRNA expression.

\section{Materials and methods}

Strains

Bristol strain N2 was used as the standard wild-type strain. All strains were grown at $20^{\circ} \mathrm{C}$ unless specified. The strains used in this study are listed in Supplemental Table S3.

\section{Antibody production}

Antibodies against PRDE-1 and TOFU-5 were produced at the Laboratory Animal Resources (European Molecular Biology Laboratory, Heidelberg). For this, New Zealand White female rabbits were immunized with the recombinant full-length proteins together with complete Freund's adjuvant. After the priming immunization, four further booster immunizations were performed every $3 \mathrm{wk}$. The harvested serum was purified by affinity purification using the recombinant full-length PRDE-1 or TOFU-5, respectively.

\section{Immunoprecipitation and MS analysis}

Nonsynchronized transgenic animals expressing TOFU-5::GFP or TOFU-5 $\left({ }^{*}\right.$ SANT)::GFP were resuspended in an equal volume of $2 \times$ lysis buffer $(50 \mathrm{mM}$ Tris- $\mathrm{HCl}$ at $\mathrm{pH} 8.0,300 \mathrm{mM} \mathrm{NaCl}, 10 \%$ glycerol, $1 \%$ Triton X-100, Roche Complete EDTA-free protease inhibitor cocktail, $10 \mathrm{mM} \mathrm{NaF}, 2 \mathrm{mM} \mathrm{Na}_{3} \mathrm{VO}_{4}$ ) and lysed in a FastPrep-24 5G homogenizer. The supernatant of lysate was incubated with homemade anti-GFP beads for $1 \mathrm{~h}$ at $4^{\circ} \mathrm{C}$. The beads were then washed three times with cold lysis buffer. Proteins were eluted with chilled elution buffer $(100 \mathrm{mM}$ glycine- $\mathrm{HCl}$ at $\mathrm{pH}$ 2.5). Eluates were precipitated with TCA or cold acetone and dissolved in $100 \mathrm{mM}$ Tris $(\mathrm{pH} 8.5)$ and $8 \mathrm{M}$ urea. The proteins were reduced with TCEP, alkylated with IAA, and finally digested with trypsin overnight at $37^{\circ} \mathrm{C}$. The liquid chromatographytandem MS (LC-MS/MS) analysis of the resulting peptides and the MS data processing approaches were conducted as described previously (Feng et al. 2017). Samples were analyzed on an LTQ Orbitrap Velos Pro (Thermo Fisher Scientific) LC/MSMS system. Data were searched with Mascot (version 2.2.03; Matrix Science) using the UniProt C. elegans database, and unique 
peptides were analyzed with Scaffold 3. MS data normalization for scatter and MA plots was carried out with a custom R script. All raw data and normalized MS data are shown in Supplemental Tables S5-S8.

The wild-type strain was var. Bristol N2 (Brenner 1974), and the SX2499 (mj207) strain was a prde-1 mutant. Synchronized nematodes were collected at young adult stage in PBS with EDTA-free Complete protease inhibitor cocktail tablets (Roche) and frozen in liquid nitrogen. Qproteome cell compartment kit (Qiagen) was used to purify nuclear fractions that were diluted with PBSCM buffer ( $1 \times$ PBS, $1 \mathrm{mM} \mathrm{CaCl} 2,1 \mathrm{mM} \mathrm{MgCl}_{2}, 1 \times$ EDTAfree Complete protease inhibitor cocktail). Protein concentration was measured with BCA protein measurement kit (Pierce). AntiPRDE-1 antibody KSOJ $(0.88 \mathrm{mg} / \mathrm{mL})$ was coupled to $5 \mu \mathrm{g}$ of Dynabeads per $1 \mathrm{mg}$ of beads according to the manufacturer's instructions. Uncoupled IgG beads were used as a control. Beads were incubated with nuclear extracts overnight at $4^{\circ} \mathrm{C}$ and washed eight times with PBSCM, and proteins were eluted in $80 \mu \mathrm{L}$ of elution buffer (100 mM TAEB, 4\% SDS) by boiling for $30 \mathrm{~min}$ at $60^{\circ} \mathrm{C}$. The elutes were precipitated in TCA or cold acetone and dissolved in $100 \mathrm{mM}$ Tris $(\mathrm{pH} 8.5)$ and $8 \mathrm{M}$ urea. The proteins were reduced with TCEP and alkylated with IAA. The samples were digested with trypsin overnight at $37^{\circ} \mathrm{C}$, and each sample was run separately.

\section{Y2H analysis}

The coding sequence of the C. elegans TOFU-4 protein fragment (amino acids 1-223), the full-length C. elegans TOFU-5 protein (amino acids 1-311), the full-length C. elegans PRDE-1 protein (amino acids 1-526), and the full-length C. elegans SNPC-4 protein (amino acids 1-928) (NCBI sequence reference NM_060011.4) were PCR-amplified and cloned into pB27 as a C-terminal fusion to LexA-DBD (LexA-TOFU4, LexA-TOFU5, LexA-SNPC-4, and LexA-Prde-1). Constructs were checked by sequencing the entire insert and used as bait to screen a randomprimed C. elegans mixed-stage cDNA library constructed into pP6. pB27 and pP6 were derived from the original pBTM1 16 (Vojtek and Hollenberg 1995) and pGADGH plasmids, respectively. Clones $(91$ million-137 million, depending on the experiment; 10 -fold the complexity of the library) were screened using a mating approach with YHGX13 (Y187 ade2-101::1oxP-kanMX-1oxP, $M A T$ ) and L40:Gal4 (MAT) yeast strains as described previously (Fromont-Racine et al. 1997). Depending on the bait, 148-365 $\mathrm{His}^{+}$colonies were selected on a medium lacking tryptophan, leucine, and histidine or supplemented with $0.5 \mathrm{mM} 3$-aminotriazole to handle bait autoactivation for LexA-Prde-1. The prey fragments of the positive clones were amplified by PCR and sequenced at their $5^{\prime}$ and $3^{\prime}$ junctions. The resulting sequences were used to identify the corresponding interacting proteins in the GenBank database (NCBI) using a fully automated procedure. A confidence score (PBS [predicted biological score]) was attributed to each interaction as described previously (Formstecher et al. 2005). The PBS scores have been shown to positively correlate with the biological significance of interactions (Rain et al. 2001; Wojcik et al. 2002). $\mathrm{Y} 2 \mathrm{H}$ screening was performed with the help of Hybrigenics Services.

\section{Size exclusion chromatography}

Five milliliters of worm nuclear extract, prepared using a Qproteome cell compartment kit (Qiagen), was injected into a Superose 6 xK 16/70 (GE Healthcare). One-milliliter fractions (starting after the void volume of $40 \mathrm{~mL}$ ) were collected, and proteins were precipitated with TCA, separated by gel electrophoresis, and transferred to a nitrocellulose membrane using a semidry transfer system (Bio-Rad).

Construction of plasmids and transgenic strains

For TOFU-4::GFP, a TOFU-4 promoter and CDS region were PCR-amplified with the primers $5^{\prime}$-GCAGATCTTCGAATGC ATCGAATTGAAAATGAGAAAAAACTG- $3^{\prime}$ and $5^{\prime}$-ATAGCT CCACCTCCACCTCCGAATTCTGCGTCTACCATCA-3' from N2 genomic DNA. A GFP::3xFlag region was PCR-amplified with the primers $5^{\prime}$-GGAGGTGGAGGTGGAGCTATGAGTAA AGGAGAAGAAC-3' and 5'-TCACTTGTCATCGTCATCCT-3' from plasmid pSG085. A TOFU-4 3' UTR (untranslated region) was PCR-amplified with the primers $5^{\prime}$-AGGATGACGATGAC AAGTGAAAGAATTTTTATCCGAGTCAC-3' and 5'-AGAT ATCCTGCAGGAATTCCGAAACTTGATTTTCAAAATTTA-3' from N2 genomic DNA. The ClonExpress MultiS one-step cloning kit (Vazyme, C113-02) was used to insert the TOFU-4:: GFP::3xFlag fusion gene into the pCFJ151 vector. The transgene was integrated onto the C. elegans chromosome II by the MosSCI method (Frokjaer-Jensen et al. 2008).

For TOFU-5::GFP, a TOFU-5 promoter and CDS region were PCR-amplified with the primers 5'-GCAGATCTTCGAATG CATCGTTGGTTCAACCTGGAATTAA- $3^{\prime}$ and $5^{\prime}$-ATAGCTC CACCTCCACCTCCATTGGACGATGTAGATGGCTG-3' from N2 genomic DNA. A GFP::3xFlag region was PCR-amplified with the primers 5'-GGAGGTGGAGGTGGAGCTATGAGTA AAGGAGAAGAAC-3' and 5'-AAAAATTTCACTTGTCATCG TCATCCTTGT-3' from plasmid pSG085. A TOFU-5 3' UTR was PCR-amplified with the primers $5^{\prime}$-CGATGACAAGTGA AATTTTTATTAATTTTTTG-3' and $5^{\prime}$-AGATATCCTGCAGG AATTCCCATGGCTTGGAATTGAAG-3' from N2 genomic DNA. The ClonExpress MultiS one-step cloning kit (Vazyme, C113-02) was used to insert the TOFU-5::GFP::3xFlag fusion gene into the pCFJ151 vector. The transgene was integrated onto the C. elegans chromosome II by the MosSCI system.

For TOFU-5(*SANT)::GFP, plasmid was PCR-amplified with the primers $5^{\prime}$-TCGCAGCTTCATCGAAGAGATAAAGTAAG T-3' and 5'-TCTCTTCGATGAAGCTGCGACCTTCTGCGA-3' from TOFU-5::GFP::3xFlag plasmid. The transgene was integrated onto the C. elegans chromosome II by the MosSCI system.

\section{RNAi}

RNAi experiments were conducted as described previously (Timmons et al. 2001). Images were collected using a Leica DM2500 microscope.

\section{ChIP}

ChIP experiments were performed as described previously with hypochlorite-isolated embryos or young adults (Guang et al. 2010). Animals were cross-linked in $2 \%$ formaldehyde for $30 \mathrm{~min}$. Fixation was quenched with $0.125 \mathrm{M}$ glycine for $5 \mathrm{~min}$ at room temperature. After cross-linking, samples were resuspended in FA buffer $(50 \mathrm{mM}$ Tris/ $\mathrm{HCl}$ at $\mathrm{pH} 7.5,1 \mathrm{mM}$ EDTA, $1 \%$ Triton X-100, $0.1 \%$ sodium deoxycholate, $150 \mathrm{mM} \mathrm{NaCl}$ ) with a proteinase inhibitor tablet (Roche, 04693116001) and sonicated for 20 cycles at medium output (each cycle: $30 \mathrm{sec}$ on and $30 \mathrm{sec}$ off) with a Bioruptor 200. Lysates were precleared and then immunoprecipitated with $1.5 \mu \mathrm{L}$ of anti-GFP antibody (Abcam, ab290) for SNPC-4, TOFU-4, and TOFU-5 and $5 \mu \mathrm{L}$ of antiPRDE-1 for PRDE-1 overnight at $4^{\circ} \mathrm{C}$. Antibody-bound complexes were recovered with Dynabeads Protein A. Following extensive sequential washes with 150,500 , and $1 \mathrm{M} \mathrm{NaCl}$, DNA was 
treated with RNase (Roche) and ProK (New England Biolabs). Finally, resulting DNA samples were purified with QIAquick PCR purification kit (Qiagen, 28104).

\section{ChIP-seq}

The DNA samples from ChIP experiments were sent to in-house sequencing for library preparation and sequencing. Briefly, 10-300 ng of ChIP DNA was combined with End Repair Mix and incubated for $30 \mathrm{~min}$ at $20^{\circ} \mathrm{C}$ followed by purification with a QIAquick PCR purification kit (Qiagen). The DNA was then incubated with A-tailing mix for $30 \mathrm{~min}$ at $37^{\circ} \mathrm{C}$. The $3^{\prime}$ end adenylated DNA was incubated with the adapter in the ligation mix for $15 \mathrm{~min}$ at $20^{\circ} \mathrm{C}$. The adapter-ligated DNA was amplified by several rounds of PCR amplification and purified using a $2 \%$ agarose gel to recover the target fragments. The average molecule length was analyzed on the Agilent 2100 bioanalyzer instrument (Agilent DNA 1000 Reagents). The library was quantified by qPCR (TaqMan probe). The libraries were further amplified on cBot to generate the clusters on the flow cell and sequenced with a single-end 50 method on a HiSeq1500 system.

\section{Alignment to reference genome for ChIP-seq data}

Chip-seq libraries were sequenced using Illumina HiSeq. Reads were aligned to the ce11 assembly of the C. elegans genome using BWA version 0.7.7 (Li and Durbin 2010) with default settings (BWA-backtrack algorithm). The SAMtools version 0.1.19 "view" utility was used to convert the alignments to BAM format. Normalized ChIP-seq coverage tracks were generated using the BEADS (bias elimination algorithm for deep sequencing) algorithm (Cheung et al. 2011).

\section{Summed ChIP-seq input and in-house blacklist}

We generated summed input BAM files by combining good quality ChIP-seq input experiments from different extracts (eight experiments for formaldehyde and five experiments for EGS extracts). The same summed inputs were used for BEADS normalization and peak calls. We observed that despite using input files for MACS2 (Zhang et al. 2008) and filtering against modENCODE, some regions of high signal in input were still called as peaks. To overcome this problem, we created an in-house blacklist by running MACS2 with default settings and no input mode. The blacklist regions were refined by discarding regions with a MACS2 score $<100$ and clustering peaks within 500 base pairs (bp). This procedure created 90 new regions in addition to 122 already covered by the modENCODE blacklist.

\section{Peak calls}

ChIP-seq peaks were called using MACS2 version 2.1.1 (Feng et al. 2012) with a permissive $0.05 q$-value cut-off and a fragment size of 150 bp against summed ChIP-seq input. To generate sharp peak call sets, we obtained peak summits and extended them 150 bp upstream and downstream, creating 300-bp regions around summit calls. Furthermore, we combined ChIP-seq replicates by intersecting these regions and setting the final peak size back to 300 bp. Finally, peaks overlapping nonmappable (GEM mappability $<25 \%$ ) or blacklisted regions were discarded. This produced sharp uniform peaks suitable for further quantitative analyses.

\section{Peak call annotation}

PRDE-1, SNPC-4, TOFU-4, and TOFU-5 peak calls were classified using selected annotations from Ensembl version 92. The peak was assigned to a given class if it directly overlapped with annotated loci. The assignments were exclusive (a peak could be assigned to only a single class), giving the following order of priority: snRNA, snoRNA, transfer RNA (tRNA), miRNA, large intergenic ncRNA (lincRNA), ncRNA, promoter, and gene body. Promoters were defined as 500 bases upstream of annotated TSSs. The overlap significance was estimated using a hypergeometric test for overrepresentation.

\section{ChIP-seq data aggregation and visualization}

SeqPlots (Stempor and Ahringer 2016) software was used to visualize PRDE-1, SNPC-4, TOFU-4, and TOFU-5 ChIP-seq profiles over Ruby motif locus, piRNAs gene, snRNA, and tRNA average as average aggregated plots and heat maps. The Integrative Genomics Viewer genome browser (Robinson et al. 2011) was applied to visualize signals genome-wide and on piRNA clusters.

\section{ChIP-seq signal quantifications}

To quantify differences in PRDE-1, SNPC-4, TOFU-4, and TOFU5 binding between piRNA clusters and somatic chromosomes, we quantified the BEADS-normalized $\log _{2}$-scaled signal in $1-\mathrm{kb}$ bins divided into piRNA clusters and chromosomes I, II, III, and V. The signal was obtained using the bigWigSummary utility from the Kent library (Kent et al. 2010) implemented in rtracklayer package in R. Next, the signal was represented as an overlaid violin plot (showing signal distribution) and Tukey box plot (showing estimation of statistical significance of difference between medians as notches).

\section{Statistics}

Bar graphs with error bars are presented with mean and standard deviation. All of the experiments were conducted with independent C. elegans animals for the indicated $N$ times. Statistical analysis was performed with two-tailed Student's $t$-test.

\section{Data availability}

All raw and normalized sequencing data have been deposited to Gene Expression Omnibus under submission number GSE112682.

\section{piRNA gene annotations}

piRNA annotations were downloaded from the piRBase online database (http://www.regulatoryrna.org/database/piRNA). Genomic coordinates of piRNA genes were obtained by SAMtools against the C. elegans ce10 genome assembly. Type II piRNA genes were obtained from a previous publication $(\mathrm{Gu}$ et al. 2012). Type I piRNA gene lists were created by filtering the piRBase annotations with type II piRNA genes.

\section{Acknowledgments}

We are grateful to the members of the Guang laboratory and Miska laboratory for their comments. We thank the Laboratory Animal Resources as well as the Protein Expression and Purification and the Proteomics Core Facilities at European Molecular Biology Laboratory (EMBL), Heidelberg, for materials and 
technical support. We are grateful to the International C. elegans Gene Knockout Consortium and the National Bioresource Project for providing the strains. Some strains were provided by the Caenorhabditis Genetics Center (CGC), which is funded by the National Institutes of Health Office of Research Infrastructure Programs (P40 OD010440). This work was supported by grants from the Chinese Ministry of Science and Technology (2017YFA0102903 and 2014CB84980001), the National Natural Science Foundation of China $(81501329,31371323,31671346$, and 91640110), the Anhui Natural Science Foundation (1608085MC50), the Beijing Municipal Science and Technology Commission (fund for cultivation and development of innovation base), Cancer Research UK (C13474/A18583 and C6946/ A14492), and the Wellcome Trust (104640/Z/14/Z and 092096/ Z/10/Z). A.C.B. is supported by a Marie Skladowska Curie PostDoctoral Fellowship.

Author contributions: C.W., S.G., A.C.B, J.K., J.A., and E.A.M. wrote the manuscript with input from their coauthors. A.C.B., C.W., and P.S. analyzed the sequencing data. C.W., J.K., A.C.B., X.F., H.M., C. Zeng, W.-J.L., Y.-H.Y., and M.-Q.D. performed the experiments. C. Zuliani performed the size exclusion chromatography analysis; O.B., N.R.M., and C. Zuliani generated the antibodies and performed the MS run; and O.B., C. Zuliani, J.K., and A.C.B. performed the MS analysis. E.A.M. and S.G. conceived the project and coordinated the studies.

\section{References}

Andersen PR, Tirian L, Vunjak M, Brennecke J. 2017. A heterochromatin-dependent transcription machinery drives piRNA expression. Nature 549: 54-59. doi:10.1038/nature23482

Aravin AA, Sachidanandam R, Bourc'his D, Schaefer C, Pezic D, Toth KF, Bestor T, Hannon GJ. 2008. A piRNA pathway primed by individual transposons is linked to de novo DNA methylation in mice. Mol Cell 31: 785-799. doi:10.1016/ j.molcel.2008.09.003

Ashe A, Sapetschnig A, Weick EM, Mitchell J, Bagijn MP, Cording AC, Doebley AL, Goldstein LD, Lehrbach NJ, Le Pen J, et al. 2012. piRNAs can trigger a multigenerational epigenetic memory in the germline of C. elegans. Cell 150: 88-99. doi:10.1016/j.cell.2012.06.018

Bagijn MP, Goldstein LD, Sapetschnig A, Weick EM, Bouasker S, Lehrbach NJ, Simard MJ, Miska EA. 2012. Function, targets, and evolution of Caenorhabditis elegans piRNAs. Science 337: 574-578. doi:10.1126/science.1220952

Batista PJ, Ruby JG, Claycomb JM, Chiang R, Fahlgren N, Kasschau KD, Chaves DA, Gu W, Vasale JJ, Duan S, et al. 2008. PRG-1 and 21U-RNAs interact to form the piRNA complex required for fertility in C. elegans. Mol Cell 31: 67-78. doi:10.1016/j.molcel.2008.06.002

Billi AC, Alessi AF, Khivansara V, Han T, Freeberg M, Mitani S, Kim JK. 2012. The Caenorhabditis elegans HEN1 ortholog, HENN-1, methylates and stabilizes select subclasses of germline small RNAs. PLoS Genet 8: e1002617. doi:10.1371/ journal.pgen.1002617

Boyer LA, Latek RR, Peterson CL. 2004. The SANT domain: a unique histone-tail-binding module? Nat Rev Mol Cell Biol 5: 158-163. doi:10.1038/nrm1314

Brennecke J, Aravin AA, Stark A, Dus M, Kellis M, Sachidanandam R, Hannon GJ. 2007. Discrete small RNA-generating loci as master regulators of transposon activity in Drosophila. Cell 128: 1089-1103. doi:10.1016/j.cell.2007.01.043

Brenner S. 1974. The genetics of Caenorhabditis elegans. Genetics 77: 71-94.
Carmell MA, Girard A, van de Kant HJ, Bourc'his D, Bestor TH, de Rooij DG, Hannon GJ. 2007. MIWI2 is essential for spermatogenesis and repression of transposons in the mouse male germline. Dev Cell 12: 503-514. doi:10.1016/j.devcel.2007. 03.001

Cecere G, Zheng GX, Mansisidor AR, Klymko KE, Grishok A. 2012. Promoters recognized by forkhead proteins exist for individual 21U-RNAs. Mol Cell 47: 734-745. doi:10.1016/ j.molcel.2012.06.021

Chalker DL, Yao MC. 2011. DNA elimination in ciliates: transposon domestication and genome surveillance. Annu Rev Genet 45: 227-246. doi:10.1146/annurev-genet-110410-132432

Cheung MS, Down TA, Latorre I, Ahringer J. 2011. Systematic bias in high-throughput sequencing data and its correction by BEADS. Nucleic Acids Res 39: e103. doi:10.1093/nar/ gkr425

Conine CC, Moresco JJ, Gu W, Shirayama M, Conte D Jr, Yates JR III, Mello CC. 2013. Argonautes promote male fertility and provide a paternal memory of germline gene expression in C. elegans. Cell 155: 1532-1544. doi:10.1016/j.cell.2013. 11.032

Cox DN, Chao A, Baker J, Chang L, Qiao D, Lin H. 1998. A novel class of evolutionarily conserved genes defined by piwi are essential for stem cell self-renewal. Genes Dev 12: 3715-3727. doi:10.1101/gad.12.23.3715

Czech B, Hannon GJ. 2016. One loop to rule them all: the pingpong cycle and piRNA-guided silencing. Trends Biochem Sci 41: 324-337. doi:10.1016/j.tibs.2015.12.008

Das PP, Bagijn MP, Goldstein LD, Woolford JR, Lehrbach NJ, Sapetschnig A, Buhecha HR, Gilchrist MJ, Howe KL, Stark $\mathrm{R}$, et al. 2008. Piwi and piRNAs act upstream of an endogenous siRNA pathway to suppress Tc3 transposon mobility in the Caenorhabditis elegans germline. Mol Cell 31: 79-90. doi:10.1016/j.molcel.2008.06.003

de Albuquerque BF, Luteijn MJ, Cordeiro Rodrigues RJ, van Bergeijk P, Waaijers S, Kaaij LJ, Klein H, Boxem M, Ketting RF. 2014. PID-1 is a novel factor that operates during 21U-RNA biogenesis in Caenorhabditis elegans. Genes Dev 28: 683688. doi:10.1101/gad.238220.114

Egloff S, O'Reilly D, Murphy S. 2008. Expression of human snRNA genes from beginning to end. Biochem Soc Trans 36: 590-594. doi:10.1042/BST0360590

Feng X, Guang S. 2013. Small RNAs, RNAi and the inheritance of gene silencing in Caenorhabditis elegans. J Genet Genomics 40: 153-160. doi:10.1016/j.jgg.2012.12.007

Feng J, Liu T, Qin B, Zhang Y, Liu XS. 2012. Identifying ChIP-seq enrichment using MACS. Nat Protoc 7: 1728-1740. doi: 10.1038/nprot.2012.101

Feng G, Zhu Z, Li WJ, Lin Q, Chai Y, Dong MQ, Ou G. 2017. Hippo kinases maintain polarity during directional cell migration in Caenorhabditis elegans. EMBO J 36: 334-345. doi: 10.15252/embj.201695734

Formstecher E, Aresta S, Collura V, Hamburger A, Meil A, Trehin A, Reverdy C, Betin V, Maire S, Brun C, et al. 2005. Protein interaction mapping: a Drosophila case study. Genome Res 15: 376-384. doi:10.1101/gr.2659105

Frokjaer-Jensen C, Davis MW, Hopkins CE, Newman BJ, Thummel JM, Olesen SP, Grunnet M, Jorgensen EM. 2008. Singlecopy insertion of transgenes in Caenorhabditis elegans. Nat Genet 40: 1375-1383. doi:10.1038/ng.248

Fromont-Racine M, Rain JC, Legrain P. 1997. Toward a functional analysis of the yeast genome through exhaustive two-hybrid screens. Nat Genet 16: 277-282. doi:10.1038/ng0797-277 
Girard A, Sachidanandam R, Hannon GJ, Carmell MA. 2006. A germline-specific class of small RNAs binds mammalian Piwi proteins. Nature 442: 199-202.

Goh WS, Seah JW, Harrison EJ, Chen C, Hammell CM, Hannon GJ. 2014. A genome-wide RNAi screen identifies factors required for distinct stages of C. elegans piRNA biogenesis. Genes Dev 28: 797-807. doi:10.1101/gad.235622.113

Goriaux C, Desset S, Renaud Y, Vaury C, Brasset E. 2014. Transcriptional properties and splicing of the flamenco piRNA cluster. EMBO Rep 15: 411-418. doi:10.1002/embr. 201337898

Gou LT, Kang JY, Dai P, Wang X, Li F, Zhao S, Zhang M, Hua MM, Lu Y, Zhu Y, et al. 2017. Ubiquitination-deficient mutations in human Piwi cause male infertility by impairing histoneto-protamine exchange during spermiogenesis. Cell 169: 1090-1104.e13. doi:10.1016/j.cell.2017.04.034

Grishok A. 2013. Biology and mechanisms of short RNAs in Caenorhabditis elegans. Adv Genet 83: 1-69.

$\mathrm{Gu}$ W, Lee HC, Chaves D, Youngman EM, Pazour GJ, Conte D Jr, Mello CC. 2012. CapSeq and CIP-TAP identify Pol II start sites and reveal capped small RNAs as C. elegans piRNA precursors. Cell 151: 1488-1500. doi:10.1016/j.cell.2012.11.023

Guang S, Bochner AF, Burkhart KB, Burton N, Pavelec DM, Kennedy S. 2010. Small regulatory RNAs inhibit RNA polymerase II during the elongation phase of transcription. Nature 465: 1097-1101. doi:10.1038/nature09095

Handler D, Olivieri D, Novatchkova M, Gruber FS, Meixner K, Mechtler K, Stark A, Sachidanandam R, Brennecke J. 2011. A systematic analysis of Drosophila TUDOR domain-containing proteins identifies Vreteno and the Tdrd12 family as essential primary piRNA pathway factors. $E M B O J \mathbf{3 0}$ : 3977-3993. doi:10.1038/emboj.2011.308

Houwing S, Kamminga LM, Berezikov E, Cronembold D, Girard A, van den Elst H, Filippov DV, Blaser H, Raz E, Moens CB, et al. 2007. A role for Piwi and piRNAs in germ cell maintenance and transposon silencing in Zebrafish. Cell 129: 6982. doi:10.1016/j.cell.2007.03.026

Ipsaro JJ, Haase AD, Knott SR, Joshua-Tor L, Hannon GJ. 2012. The structural biochemistry of Zucchini implicates it as a nuclease in piRNA biogenesis. Nature 491: 279-283. doi: 10.1038/nature11502

Kasper DM, Wang G, Gardner KE, Johnstone TG, Reinke V. 2014. The C. elegans SNAPc component SNPC-4 coats piRNA domains and is globally required for piRNA abundance. Dev Cell 31: 145-158. doi:10.1016/j.devcel.2014.09.015

Kent WJ, Zweig AS, Barber G, Hinrichs AS, Karolchik D. 2010. BigWig and BigBed: enabling browsing of large distributed datasets. Bioinformatics 26: 2204-2207. doi:10.1093/ bioinformatics/btq351

Kim KW, Tang NH, Andrusiak MG, Wu Z, Chisholm AD, Jin Y. 2018. A neuronal piRNA pathway inhibits axon regeneration in C. elegans. Neuron 97: 511-519.e6. doi:10.1016/j.neuron. 2018.01.014

Kiuchi T, Koga H, Kawamoto M, Shoji K, Sakai H, Arai Y, Ishihara G, Kawaoka S, Sugano S, Shimada T, et al. 2014. A single female-specific piRNA is the primary determiner of sex in the silkworm. Nature 509: 633-636. doi:10.1038/nature13315

Klattenhoff C, Theurkauf W. 2008. Biogenesis and germline functions of piRNAs. Development 135: 3-9. doi:10.1242/dev. 006486

Klattenhoff C, Xi H, Li C, Lee S, Xu J, Khurana JS, Zhang F, Schultz N, Koppetsch BS, Nowosielska A, et al. 2009. The Drosophila HP1 homolog Rhino is required for transposon silencing and piRNA production by dual-strand clusters. Cell 138: 1137-1149. doi:10.1016/j.cell.2009.07.014
Lee HC, Gu W, Shirayama M, Youngman E, Conte D Jr, Mello CC. 2012. C. elegans piRNAs mediate the genome-wide surveillance of germline transcripts. Cell 150: 78-87. doi: 10.1016/j.cell.2012.06.016

Li H, Durbin R. 2010. Fast and accurate long-read alignment with Burrows-Wheeler transform. Bioinformatics 26: 589-595. doi:10.1093/bioinformatics/btp698

Li XZ, Roy CK, Dong X, Bolcun-Filas E, Wang J, Han BW, Xu J, Moore MJ, Schimenti JC, Weng Z, et al. 2013. An ancient transcription factor initiates the burst of piRNA production during early meiosis in mouse testes. Mol Cell 50: 67-81. doi: 10.1016/j.molcel.2013.02.016

Lin H, Spradling AC. 1997. A novel group of pumilio mutations affects the asymmetric division of germline stem cells in the Drosophila ovary. Development 124: 2463-2476.

Luteijn MJ, Ketting RF. 2013. PIWI-interacting RNAs: from generation to transgenerational epigenetics. Nat Rev Genet 14: 523-534. doi:10.1038/nrg3495

Lykke-Andersen S, Jensen TH. 2007. Overlapping pathways dictate termination of RNA polymerase II transcription. Biochimie 89: 1177-1182. doi:10.1016/j.biochi.2007.05.007

Malone CD, Hannon GJ. 2009. Molecular evolution of piRNA and transposon control pathways in Drosophila. Cold Spring Harb Symp Quant Biol 74: 225-234. doi:10.1101/sqb.2009. 74.052

Mao H, Zhu C, Zong D, Weng C, Yang X, Huang H, Liu D, Feng X, Guang S. 2015. The Nrde pathway mediates small-RNA-directed histone $\mathrm{H} 3$ lysine 27 trimethylation in Caenorhabditis elegans. Curr Biol 25: 2398-2403. doi:10.1016/j.cub.2015. 07.051

Mohn F, Sienski G, Handler D, Brennecke J. 2014. The rhinodeadlock-cutoff complex licenses noncanonical transcription of dual-strand piRNA clusters in Drosophila. Cell 157: 13641379. doi:10.1016/j.cell.2014.04.031

Montgomery TA, Rim YS, Zhang C, Dowen RH, Phillips CM, Fischer SE, Ruvkun G. 2012. PIWI associated siRNAs and piRNAs specifically require the Caenorhabditis elegans HEN1 ortholog henn-1. PLoS Genet 8: e1002616. doi:10.1371/ journal.pgen.1002616

Palakodeti D, Smielewska M, Lu YC, Yeo GW, Graveley BR. 2008. The PIWI proteins SMEDWI-2 and SMEDWI-3 are required for stem cell function and piRNA expression in planarians. RNA 14: 1174-1186. doi:10.1261/rna.1085008

Pane A, Jiang P, Zhao DY, Singh M, Schupbach T. 2011. The Cutoff protein regulates piRNA cluster expression and piRNA production in the Drosophila germline. EMBO I 30: 46014615. doi:10.1038/emboj.2011.334

Rain JC, Selig L, De Reuse H, Battaglia V, Reverdy C, Simon S, Lenzen G, Petel F, Wojcik J, Schachter V, et al. 2001. The protein-protein interaction map of Helicobacter pylori. Nature 409: 211-215. doi:10.1038/35051615

Reddien PW, Oviedo NJ, Jennings JR, Jenkin JC, Sanchez Alvarado A. 2005. SMEDWI-2 is a PIWI-like protein that regulates planarian stem cells. Science 310: 1327-1330. doi:10.1126/ science. 1116110

Robinson JT, Thorvaldsdóttir H, Winckler W, Guttman M, Lander ES, Getz G, Mesirov JP. 2011. Integrative genomics viewer. Nat Biotechnol 29: 24-26. doi:10.1038/nbt.1754

Ruby JG, Jan C, Player C, Axtell MJ, Lee W, Nusbaum C, Ge H, Bartel DP. 2006. Large-scale sequencing reveals 21U-RNAs and additional microRNAs and endogenous siRNAs in C. elegans. Cell 127: 1193-1207. doi:10.1016/j.cell.2006.10.040

Saito K, Sakaguchi Y, Suzuki T, Suzuki T, Siomi H, Siomi MC. 2007. Pimet, the Drosophila homolog of HEN1, mediates 
2'-O-methylation of Piwi- interacting RNAs at their 3' ends. Genes Dev 21: 1603-1608. doi:10.1101/gad.1563607

Schnettler E, Donald CL, Human S, Watson M, Siu RW, McFarlane M, Fazakerley JK, Kohl A, Fragkoudis R. 2013. Knockdown of piRNA pathway proteins results in enhanced Semliki Forest virus production in mosquito cells. J Gen Virol 94: 1680-1689. doi:10.1099/vir.0.053850-0

Seth M, Shirayama M, Gu W, Ishidate T, Conte D Jr, Mello CC. 2013. The C. elegans CSR-1 argonaute pathway counteracts epigenetic silencing to promote germline gene expression. Dev Cell 27: 656-663. doi:10.1016/j.devcel.2013.11.014

Shirayama M, Seth M, Lee HC, Gu W, Ishidate T, Conte D Jr, Mello CC. 2012. piRNAs initiate an epigenetic memory of nonself RNA in the C. elegans germline. Cell 150: 65-77. doi:10.1016/ j.cell.2012.06.015

Siomi MC, Sato K, Pezic D, Aravin AA. 2011. PIWI-interacting small RNAs: the vanguard of genome defence. Nat Rev Mol Cell Biol 12: 246-258. doi:10.1038/nrm3089

Stempor P, Ahringer J. 2016. SeqPlots-interactive software for exploratory data analyses, pattern discovery and visualization in genomics. Wellcome Open Res 1: 14. doi:10.12688/ wellcomeopenres.10004.1

Tang W, Tu S, Lee HC, Weng Z, Mello CC. 2016. The RNase PARN-1 trims piRNA $3^{\prime}$ ends to promote transcriptome surveillance in C. elegans. Cell 164: 974-984. doi:10.1016/j.cell. 2016.02.008

Timmons L, Court DL, Fire A. 2001. Ingestion of bacterially expressed dsRNAs can produce specific and potent genetic inter- ference in Caenorhabditis elegans. Gene 263: 103-112. doi: 10.1016/S0378-1119(00)00579-5

Vojtek AB, Hollenberg SM. 1995. Ras-Raf interaction: two-hybrid analysis. Methods Enzymol 255: 331-342. doi:10.1016/ S0076-6879(95)55036-4

Vourekas A, Zheng K, Fu Q, Maragkakis M, Alexiou P, Ma J, Pillai RS, Mourelatos Z, Wang PJ. 2015. The RNA helicase MOV10L1 binds piRNA precursors to initiate piRNA processing. Genes Dev 29: 617-629. doi:10.1101/gad.254631.114

Wang G, Reinke V. 2008. A C. elegans Piwi, PRG-1, regulates 21U-RNAs during spermatogenesis. Curr Biol 18: 861-867. doi:10.1016/j.cub.2008.05.009

Weick EM, Sarkies P, Silva N, Chen RA, Moss SM, Cording AC, Ahringer J, Martinez-Perez E, Miska EA. 2014. PRDE-1 is a nuclear factor essential for the biogenesis of Ruby motif-dependent piRNAs in C. elegans. Genes Dev 28: 783-796. doi: $10.1101 /$ gad.238105.114

Wojcik J, Boneca IG, Legrain P. 2002. Prediction, assessment and validation of protein interaction maps in bacteria. J Mol Biol 323: 763-770. doi:10.1016/S0022-2836(02)01009-4

Zhang Y, Liu T, Meyer CA, Eeckhoute J, Johnson DS, Bernstein BE, Nusbaum C, Myers RM, Brown M, Li W, et al. 2008. Model-based analysis of ChIP-seq (MACS). Genome Biol 9: R137. doi:10.1186/gb-2008-9-9-r137

Zhao S, Gou LT, Zhang M, Zu LD, Hua MM, Hua Y, Shi HJ, Li Y, Li J, Li D, et al. 2013. piRNA-triggered MIWI ubiquitination and removal by APC/C in late spermatogenesis. Dev Cell 24: 13-25. doi:10.1016/j.devcel.2012.12.006 


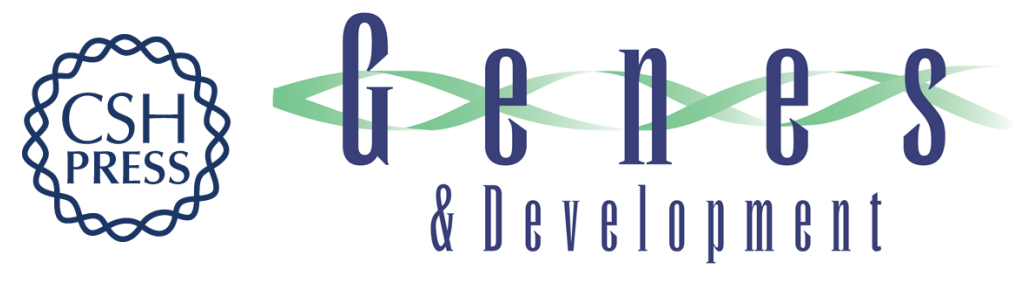

\section{The USTC co-opts an ancient machinery to drive piRNA transcription in C. elegans}

Chenchun Weng, Joanna Kosalka, Ahmet C. Berkyurek, et al.

Genes Dev. 2019, 33: originally published online December 19, 2018

Access the most recent version at doi:10.1101/gad.319293.118

\section{Supplemental http://genesdev.cshlp.org/content/suppl/2018/12/19/gad.319293.118.DC1 Material}

References This article cites 72 articles, 15 of which can be accessed free at: http://genesdev.cshlp.org/content/33/1-2/90.full.html\#ref-list-1

Creative This article, published in Genes \& Development, is available under a Creative Commons Commons License (Attribution 4.0 International), as described at License http://creativecommons.org/licenses/by/4.0/.

Email Alerting Receive free email alerts when new articles cite this article - sign up in the box at the top Service right corner of the article or click here.

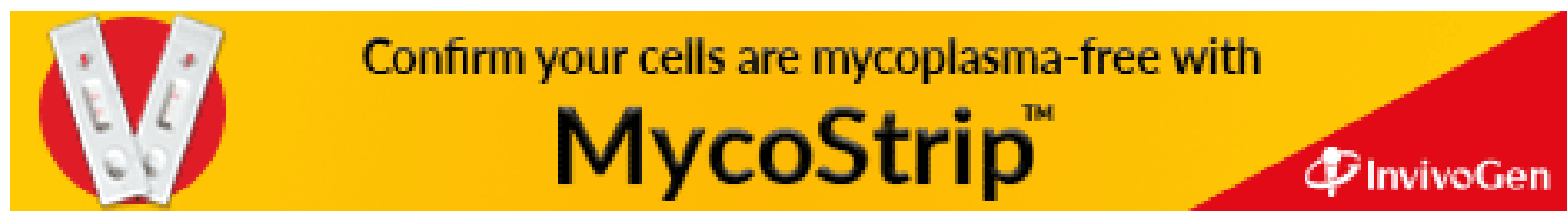

